\title{
Erratum to: Inhibition of triclabendazole metabolism in vitro by ketoconazole increases disruption to the tegument of a triclabendazole-resistant isolate of Fasciola hepatica
}

\author{
C. Devine • G. P. Brennan • C. E. Lanusse • \\ L. I. Alvarez • A. Trudgett • E. Hoey $\cdot$ I. Fairweather
}

Received: 1 February 2011 / Accepted: 10 February 2011 / Published online: 14 August 2011

(C) Springer-Verlag 2011

\section{Erratum to: Parasitol Res \\ DOI 10.1007/s00436-011-2304-9}

\begin{abstract}
A study has been carried out to investigate whether the action of triclabendazole (TCBZ) against Fasciola hepatica is altered by inhibition of drug metabolism. The cytochrome P450 (CYP 450) enzyme pathway was inhibited using ketoconazole (KTZ) to see whether a TCBZ-resistant isolate could be made more sensitive to TCBZ action. The Oberon TCBZ-resistant and Cullompton TCBZ-susceptible isolates were used for these experiments. The CYP 450 system was inhibited by a 2 -h pre-incubation in ketoconazole $(40 \mu \mathrm{M})$, then incubated for a further $22 \mathrm{~h}$ in NCTC medium containing either $\mathrm{KTZ}, \mathrm{KTZ}+$ nicotinamide adenine dinucleotide phosphate (NADPH) $(1 \mathrm{nM}), \mathrm{KTZ}+\mathrm{NADPH}+$ TCBZ $(15 \mu \mathrm{g} / \mathrm{ml})$, or KTZ+NADPH+triclabendazole sulphoxide (TCBZ.SO; $15 \mu \mathrm{g} / \mathrm{ml}$ ). Changes to fluke ultrastructure following drug treatment and metabolic inhibition were assessed using transmission electron microscopy. After treatment with either TCBZ or TCBZ.SO on their own, there was greater disruption to the TCBZ-susceptible than
\end{abstract}

The online version of the original article can be found at http://dx.doi. org/10.1007/s00436-011-2304-9.

C. Devine $\cdot$ G. P. Brennan · A. Trudgett $\cdot$ E. Hoey $\cdot$

I. Fairweather $(\square)$

Parasite Therapeutics Group, School of Biological Sciences,

Medical Biology Centre, The Queen's University of Belfast,

97 Lisburn Road,

Belfast BT9 7BL, UK

e-mail: i.fairweather@qub.ac.uk

C. E. Lanusse $\cdot$ L. I. Alvarez

Laboratorio de Farmacología, Departamento de Fisiopatología,

Facultad de Ciencias Veterinarias, Universidad Nacional del

Centro de la Provincia de Buenos Aires,

Campus Universitario (UNCPBA),

7000, Tandil, Argentina
TCBZ-resistant isolate. However, co-incubation with KTZ+ TCBZ, but more particularly KTZ+TCBZ.SO, led to more severe changes to the TCBZ-resistant isolate than with each drug on its own: for example, there was severe swelling of the basal infolds and their associated mucopolysaccharide masses, accompanied by an accumulation of secretory bodies just below the apex. Golgi complexes were greatly reduced or absent in the tegumental cells and the synthesis, production, and transport of secretory bodies were badly disrupted. With the TCBZ-susceptible Cullompton isolate, there was limited potentiation of drug action. The results support the concept of altered drug metabolism in TCBZresistant flukes and this process may play a role in the development of drug resistance.

\section{Introduction}

Triclabendazole (TCBZ) remains the drug of choice for treating infections of Fasciola hepatica and is metabolised within the host, principally into its sulphoxide and sulphone metabolites. In sheep, it has been shown that this biotransformation is carried out by the flavin monooxygenase (FMO) and cytochrome P450 (CYP 450) enzyme systems (Virkel et al. 2006). The metabolism transforms the drug into more polar metabolites that are excreted more easily (Cvilink et al. 2009). F. hepatica has also been shown to have the ability to metabolise TCBZ (Mottier et al. 2004; Robinson et al. 2004). Work has shown that the metabolism is up-regulated in TCBZ-resistant isolates, as the conversion of TCBZ to triclabendazole sulphoxide (TCBZ.SO) and TCBZ.SO to triclabendazole sulphone $\left(\mathrm{TCBZ} . \mathrm{SO}_{2}\right)$ has been shown to be 
significantly higher in TCBZ-resistant isolates (Robinson et al. 2004; Alvarez et al. 2005). It is this enhancement in oxidative metabolism that has been suggested as a possible mechanism of resistance to TCBZ within the fluke. The FMO system probably represents the main pathway for the metabolism of TCBZ to TCBZ.SO, while the CYP 450 system probably plays a greater role in the conversion of TCBZ.SO to TCBZ. $\mathrm{SO}_{2}$ (Alvarez et al. 2005).

In order to deal with drug resistance and maintain productivity, it is important to understand the mechanisms that have led to the development of drug-resistant parasite populations. This investigation is part of a series of studies that have examined the role of altered drug metabolism in the development of resistance, by determining the effect of metabolic inhibitors of the FMO and CYP 450 pathways on the morphology of the fluke (Devine et al. 2009, 2010a, b, c). The aim of this study was to investigate whether the actions of TCBZ and TCBZ.SO were altered in vitro, in TCBZ-susceptible and -resistant isolates, after CYP 450 inhibition with ketoconazole (KTZ). A previous study showed that incubation in drug plus KTZ resulted in more severe surface changes to the fluke than incubation in drug alone, and that these changes were also more severe in a TCBZ-resistant isolate compared to a TCBZ-susceptible isolate (Devine et al. 2010c). As a follow-on to that study, this investigation deals with changes to fluke ultrastructure and focuses on the tegumental system of the parasite. The tegument is the main route of entry for TCBZ compounds into the fluke (Mottier et al. 2006; Toner et al. 2009, 2010a) and carries out many important functions for the parasite (Fairweather et al. 1999); therefore, it is likely to manifest the result of any changes brought about by alterations in drug metabolism.

\section{Materials and methods}

The protocol for this investigation is the same as that used for the scanning electron microscope (SEM) study involving KTZ (Devine et al. 2010c); the reader is referred to that publication for full details. Briefly, adult flukes of the Cullompton TCBZ-
Fig. 1-6 Transmission electron micrographs (TEMs) of the tegumental syncytium, underlying musculature and tegumental cells of adult Fasciola hepatica (Cullompton and Oberon isolates) treated in vitro with KTZ and KTZ+NADPH for $24 \mathrm{~h} 1 \mathrm{TEM}$ showing the full depth of the tegumental syncytium, from the apical plasma membrane $(A P M)$ to the basal lamina $(B L)$. Some swelling of the mucopolysaccharide masses (arrows) can be seen along the length of the basal infolds, although the basal infolds $(B I)$ remain tightly closed. The muscle blocks $(M u)$ beneath the basal lamina retain a normal morphology. Bar $2 \mu \mathrm{m} 2$ A high-power micrograph of the apical region of the tegumental syncytium. Numerous T1 (T1) and T2 (T2) secretory bodies are present beneath the apical plasma membrane $(A P M)$. Bar $500 \mathrm{~nm} 3$ TEM showing the basal region of the syncytium. Above the basal lamina $(B L)$, the mucopolysaccharide masses (arrow) are swollen. The mitochondria $(\mathrm{m})$ retain a relatively normal morphology. BI, basal infolds. Bar 500nm Inset highlights the abundance of $\mathrm{T} 1(T 1)$ and $\mathrm{T} 2(T 2)$ secretory bodies in the basal region. $m$, mitochondria. Bar $1 \mu \mathrm{m} 4$ TEM showing a Type- 1 and a Type-2 tegumental cell adjacent to one another. Numerous T1 (T1) secretory bodies are present within the Type-1 tegumental cell. Active, well-developed Golgi complexes $(G C)$ are present. Numerous T2 (T2) secretory bodies are present within the Type- 2 tegumental cell. The nucleus $(N)$ retains a normal morphology. $m$, mitochondria. Bar $1 \mu \mathrm{m} 5$ TEM showing two tegumental cells adjacent to one another. The nucleus $(N)$ in each cell appears normal. Numerous T1 secretory bodies (T1) are present within the Type-1 tegumental cell. The mitochondria $(\mathrm{m})$ retain a relatively normal morphology. Bar $1 \mu \mathrm{m}$ Inset shows a high-power image of a Golgi complex $(G C)$ which retains a normal morphology. Bar 200nm 6 A high-power micrograph of a Type-2 tegumental cell containing large numbers of T2 secretory bodies (T2), which appear swollen. N, nucleus. Bar 500nm

susceptible isolate and the Oberon TCBZ-resistant fluke isolates were pre-incubated in $\mathrm{KTZ}$ at a concentration of $1 \times$ $10^{-4} \mathrm{M}$ for $2 \mathrm{~h}$ at $37^{\circ} \mathrm{C}$, before transfer to fresh NCTC culture medium for $22 \mathrm{~h}$ at $37^{\circ} \mathrm{C}$ containing one of a number of drug and inhibitor combinations (Table 1). A stock solution of ketoconazole was initially prepared at a concentration of $1 \times$ $10^{-1} \mathrm{M}$ in methanol. The concentration of KTZ used was chosen to be similar to those used in previous in vitro studies (Bourrie et al. 1996; Zhang et al. 2002; Dupuy et al. 2003; Virkel et al. 2006). The concentrations of TCBZ and TCBZ. SO used correspond to the maximum blood level of TCBZ. SO reached in vivo $(13.3 \mu \mathrm{g} / \mathrm{ml}$ following a therapeutic dose of $10 \mathrm{mg} / \mathrm{kg}$ TCBZ in sheep; Hennessy et al. 1987). Controls were prepared by incubating whole flukes in NCTC 135 medium for $24 \mathrm{~h}$ at $37^{\circ} \mathrm{C}$. Controls at $0 \mathrm{~h}$ were also
Table 1 Drug and inhibitor combinations

KTZ ketoconazole, NADPH nicotinamide adenine dinucleotide phosphate, TCBZ triclabendazole, TCBZ.SO triclabendazole sulphoxide

\begin{tabular}{llll}
\hline KTZ $(40 \mu \mathrm{M})$ & NADPH $(1 \mathrm{nM})$ & TCBZ $(15 \mu \mathrm{g} / \mathrm{ml})$ & TCBZ.SO $(15 \mu \mathrm{g} / \mathrm{ml})$ \\
\hline$\checkmark$ & & & \\
$\checkmark$ & $\checkmark$ & $\checkmark$ & \\
$\checkmark$ & $\checkmark$ & $\checkmark$ & $\checkmark$ \\
$\checkmark$ & $\checkmark$ & $\checkmark$ & $\checkmark$ \\
\hline
\end{tabular}




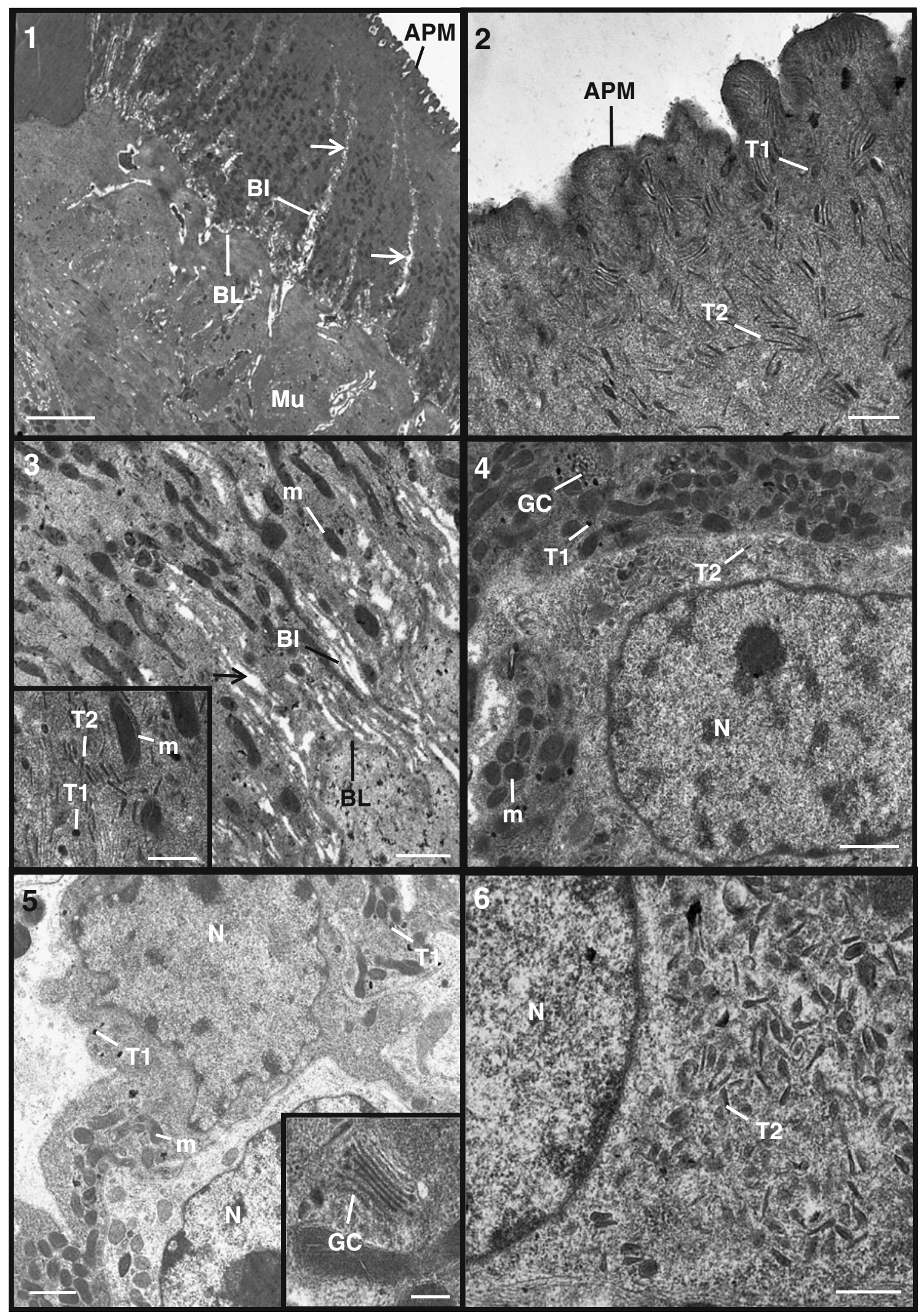

prepared. After incubation, the flukes were fixed and processed for transmission electron microscopy (TEM), as described by Devine et al. (2010b). A minimum of four flukes were prepared for each treatment. For the 
provenance of the Cullompton and Oberon isolates, see the review by Fairweather (2011).

\section{Results}

After incubation in all drug and inhibitor combinations for $24 \mathrm{~h}$ in vitro, the flukes were alive prior to fixation. Sections for TEM were taken from the midbody region of the flukes as this area was shown to be highly affected by drug and inhibitor action in a previous SEM study (Devine et al. 2010c).

\section{Controls}

The tegumental ultrastructure of the control specimens was normal. For images of normal morphology, the reader is referred to the papers by Halferty et al. (2009a, Fig. 4A-C) and Fairweather et al. (1999, Fig. 3.3 and 3.4).

\section{Oberon and Cullompton isolates treated with KTZ} and $\mathrm{KTZ}+\mathrm{NADPH}$

Within the tegumental syncytium, the mucopolysaccharide masses were swollen along the length of the basal infolds (Fig. 1). The sub-tegumental muscle blocks retained a relatively normal morphology (Fig. 1). Beneath the apical plasma membrane, $\mathrm{T} 1$ and $\mathrm{T} 2$ secretory bodies were present in normal numbers (Fig. 2). There was some swelling of the mucopolysaccharide masses surrounding the basal infolds in the basal region of the syncytium (Fig. 3). In this region, there were numerous $\mathrm{T} 1$ and $\mathrm{T} 2$ secretory bodies (Fig. 3, inset). $\mathrm{T} 1$ and $\mathrm{T} 2$ secretory bodies were present within their respective cells (Fig. 4, 5 and 6). Active Golgi complexes and numerous $\mathrm{T} 1$ secretory bodies were observed in the type- 1 cells (Fig. 5). In Type-2 tegumental cells, numerous T2 secretory bodies were present, but were swollen in appearance (Fig. 6). The nucleus in each cell type retained a normal morphology.

\section{Cullompton isolate treated with TCBZ and TCBZ.SO}

Descriptions of ultrastructural changes brought about by treatment with the two drugs have been published elsewhere and will not be repeated here. The changes observed in the present study matched these descriptions. Therefore, the reader is referred to the paper by Halferty et al. (2009a; Fig. 4D-F for TCBZ and Fig. 5A-C for TCBZ.SO). Within the tegumental syncytium, the basal infolds were swollen, particularly in the basal region. Few secretory bodies were present throughout the syncytium. Swollen mitochondria were a common feature, both in the syncytium and in the tegumental cells. Within T1type tegumental cells, secretory bodies were scarce, especially
Fig. 7-11 Transmission electron micrographs (TEMs) of the tegumental syncytium, underlying musculature and tegumental cells of adult Fasciola hepatica (Cullompton isolate) following $24 \mathrm{~h}$ in vitro treatment with KTZ + NADPH + TCBZ 7 TEM of the tegumental syncytium, from the apical plasma membrane $(A P M)$ to the basal lamina $(B L)$. Swelling of the basal infolds $(B I)$ can be seen in the basal region. The mitochondria $(m)$ in the syncytium are rounded in appearance. Bar $2 \mu \mathrm{m} 8 \mathrm{~A}$ high-power micrograph of the apical region of the syncytium. Numerous T1 $(T 1)$ and T2 (T2) secretory bodies are present beneath the apical plasma membrane $(A P M)$. Bar $1 \mu \mathrm{m} 9$ TEM showing the basal region of the syncytium. The mucopolysaccharide masses (arrow) and basal infolds $(B I)$ are swollen just above the basal lamina $(B L)$. The mitochondria $(m)$ are swollen and rounded in appearance. The fibres within the sub-tegumental muscle blocks $(M u)$ are fewer and appear more loosely-packed than normal. Bar $1 \mu \mathrm{m} 10$ Low-power micrograph of the longitudinal muscle layer $(M u)$ beneath the tegument and of the deeper-lying tegumental cells. There is spacing between the cells (arrows). The mitochondria $(m)$ have a swollen appearance, but the nuclei $(N)$ of the cells retain a normal morphology. Bar $5 \mu \mathrm{m} 11$ TEM showing two Type-1 tegumental cells. Spacing (arrows) can be seen around the cells. T1 secretory bodies (T1) are present within the cells in relatively normal numbers. Some mitochondria $(m)$ have become swollen in appearance. The nuclei $(N)$ of the cells retain a normal morphology. Bar $1 \mu \mathrm{m}$

after incubation in TCBZ.SO. Golgi complexes were reduced in number and, when present, were reduced in size. The cisternae of the granular endoplasmic reticulum (GER) were severely swollen, particularly after treatment with TCBZ.SO.

\section{Cullompton isolate treated with $\mathrm{KTZ}+\mathrm{NADPH}+\mathrm{TCBZ}$}

Within the tegumental syncytium, a marked swelling of the basal infolds was observed in the basal region (Fig. 7). In the apical region, $\mathrm{T} 1$ and $\mathrm{T} 2$ secretory bodies were present in normal numbers (Fig. 8). There was swelling of the mucopolysaccharide masses in the basal region and the mitochondria present throughout the syncytium were swollen and rounded in appearance (Fig. 9). The sub-tegumental muscle blocks contained fewer fibres than normal and the fibres were less tightly-packed than normal (Fig. 9). There was evidence of spacing between the tegumental cells (Fig. 10, 11). The Type-1 tegumental cells contained numerous T1 secretory bodies. The nuclei appeared normal, but many mitochondria were swollen and rounded in appearance (Fig. 11).

\section{Cullompton isolate treated with $\mathrm{KTZ}+\mathrm{NADPH}+\mathrm{TCBZ} . \mathrm{SO}$}

The major feature of the tegumental syncytium was swelling of the mucopolysaccharide masses at the proximal and distal ends of the basal infolds, but the latter remained tightly closed (Fig. 12). The mitochondria present throughout the syncytium appeared swollen and rounded in appearance (Fig. 12). Beneath the apical plasma membrane, T1 and T2 secretory bodies were present in normal numbers (Fig. 13). Swelling of the mucopolysaccharide masses was most evident in the basal region of the syncytium, although the 


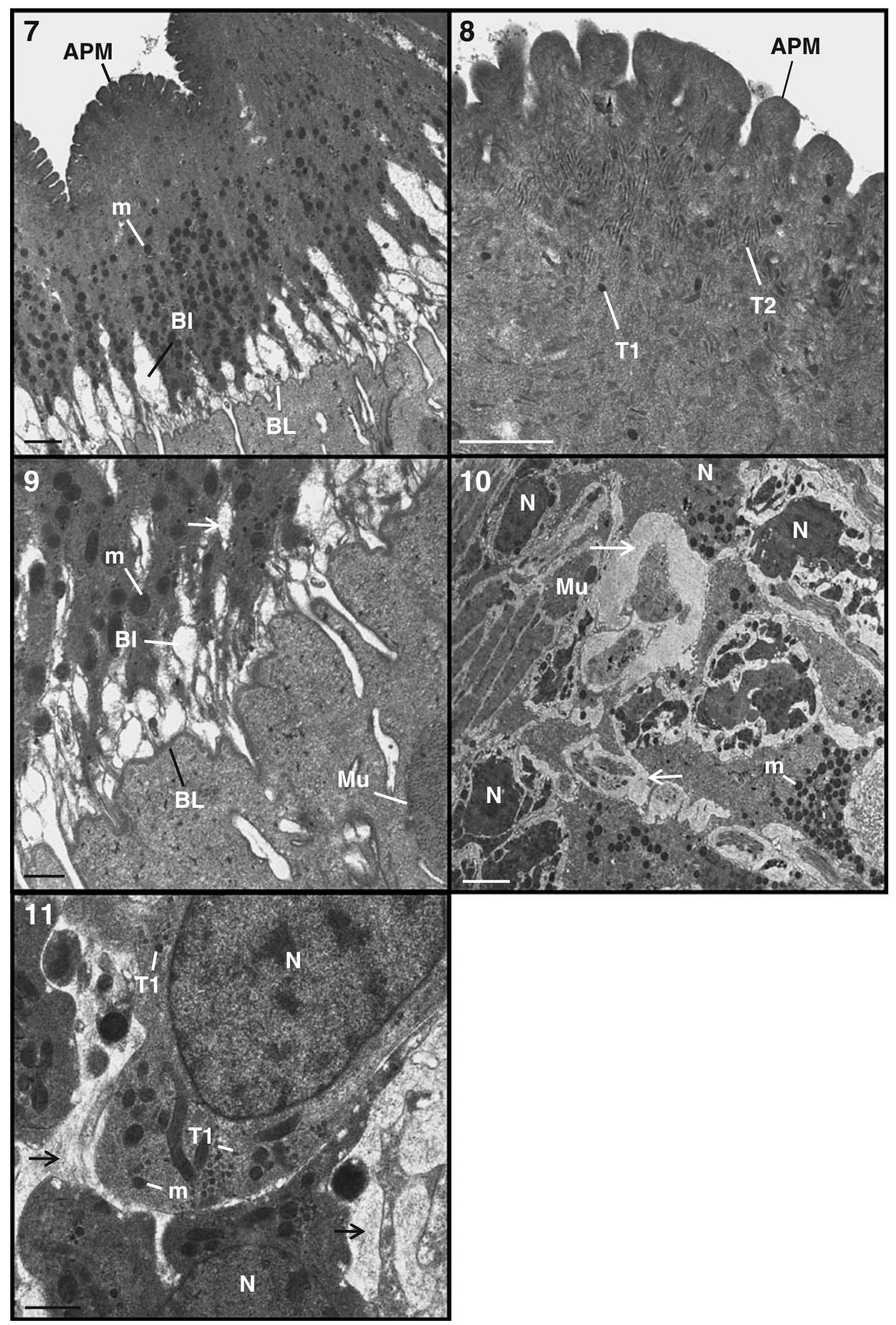


basal infolds that they surrounded were not swollen (Figs. 14, 15). T1 secretory bodies were abundant in the basal region (Figs. 14, 15). Beneath the syncytium, the sub-tegumental muscle retained a normal appearance, but there was spacing between the tegumental cells (Fig. 16). Within the tegumental cells, T1 secretory bodies were sparse and the mitochondria were swollen, but the nucleus retained a normal morphology (Fig. 17).

\section{Oberon isolate treated with TCBZ}

Descriptions of ultrastructural changes brought about by drug treatment have been given elsewhere and will not be repeated here. The changes observed in the present study matched these descriptions. Therefore, the reader is referred to Devine et al. (2010b); Figs. 12, 14, 15 and 16). Minor swelling of the mucopolysaccharide masses was observed within the tegumental syncytium. At the apex of the syncytium, a few "open" bodies were present. T1 and T2 secretory bodies were present throughout the syncytium in relatively normal numbers and the mitochondria were swollen in appearance. There were accumulations of $\mathrm{T} 2$ secretory bodies within Type-2 tegumental cells, while in Type-1 tegumental cells the T1 secretory bodies were sparse, despite the presence of active Golgi complexes. The cisternae of GER and the mitochondria in the Type-1 cells were swollen.

\section{Oberon isolate treated with TCBZ.SO}

The changes to the tegumental syncytium following incubation in TCBZ.SO have been described by McKinstry (2008; chapter 7), Figs. 15, 16, 17, 18, 19 and 20) and will not be repeated in detail here. Briefly, there was blebbing of the apical plasma membrane and "open" bodies were observed beneath the apex of the tegument. T2 secretory bodies were present in high numbers beneath the apical plasma membrane. Mitochondria within the syncytium were fewer in number than normal and were swollen and rounded in appearance. $\mathrm{T} 1$ secretory bodies accumulated towards the base of the syncytium. Swelling of the basal infolds was not observed, though the associated mucopolysaccharide masses were slightly swollen. Within the tegumental cells, secretory bodies were observed in normal numbers within their respective cells. The Golgi complexes within the T1-type tegumental cells appeared reduced in size and number.

\section{Oberon isolate treated with $\mathrm{KTZ}+\mathrm{NADPH}+\mathrm{TCBZ}$}

Swelling of the mucopolysaccharide masses surrounding the basal infolds was evident in the tegumental syncytium. This swelling extended towards the distal end of the basal infolds, although the latter remained closed in this region (Fig. 18). The underlying muscle layers retained a relatively normal
Fig. 12-17 Transmission electron micrographs (TEMs) of the tegumental syncytium, underlying musculature and tegumental cells of adult Fasciola hepatica (Cullompton isolate) following $24 \mathrm{~h}$ in vitro treatment with KTZ + NADPH + TCBZ.SO 12 TEM showing the full depth of the tegumental syncytium, from the apical plasma membrane $(A P M)$ to the basal lamina $(\mathrm{BL})$. The mitochondria $(m)$ in the syncytium are rounded in appearance. Slight swelling of the mucopolysaccharide masses (arrows) can be seen along the length of the basal infolds $(B I)$, although the latter remain tightly closed. Bar $2 \mu \mathrm{m} 13$ A high-power micrograph of the apex of the tegumental syncytium. Numerous $\mathrm{T} 1(T 1)$ and $\mathrm{T} 2(T 2)$ secretory bodies are present beneath the apical plasma membrane $(A P M)$. Bar $500 \mathrm{~nm} 14$ TEM showing the basal region of the tegumental syncytium. Above the basal lamina $(B L)$, the mucopolysaccharide masses (arrow) are swollen. The mitochondria $(m)$ are also swollen. Numerous T1 (T1) secretory bodies are present within this region. Bar $1 \mu \mathrm{m} 15$ TEM showing the basal region of the syncytium. Above the basal lamina $(B L)$, the mucopolysaccharide masses (arrows) are swollen, although the basal infolds $(B I)$ remain tightly closed. $T 1, \mathrm{~T} 1$ secretory bodies. Bar $1 \mu \mathrm{m} 16$ Low-power micrograph of sub-tegumental muscle $(M u)$, which appears normal, and underlying tegumental cells. Spaces (arrows) are present between the cells. The mitochondria $(m)$ have a swollen appearance, but the nuclei $(N)$ of the cells retain a normal morphology. Bar $5 \mu \mathrm{m} 17$ TEM of a Type-1 tegumental cell. Spaces (arrow) are present between the cells. There are few T1 secretory bodies $(T 1)$ within the cell. Some mitochondria $(m)$ have become swollen in appearance. $N$, nucleus. Bar $1 \mu \mathrm{m}$

appearance (Fig. 18). T1 and T2 secretory bodies were abundant in the apical region of the syncytium (Fig. 19). In other regions, the basal infolds above the basal lamina were swollen towards their base (Fig. 20). There were numerous $\mathrm{T} 1$ secretory bodies in the basal region and the mitochondria present were swollen and rounded in appearance (Fig. 20). Spaces were observed between the tegumental cells (Fig. 21). T1 secretory bodies were present within the cells, also well-developed Golgi complexes (Fig. 21, inset). The mitochondria were swollen in appearance, but the nucleus retained a normal morphology.

\section{Oberon isolate treated with $\mathrm{KTZ}+\mathrm{NADPH}+\mathrm{TCBZ} . \mathrm{SO}$}

The major feature of the tegumental syncytium was the severe swelling of the basal infolds (Figs. 22, 23). Secretory bodies were present in the apical region of the syncytium, with T2 secretory bodies seeming to accumulate just beneath the apical plasma membrane (Fig. 24). Swelling of the basal infolds was very evident in the basal region of the tegument and the mitochondria present within the syncytium were generally swollen and assumed a rounded appearance, rather than the typical cylindrical shape (Fig. 25). Spaces were observed between the muscle blocks and tegumental cells (Fig. 26). Within the type-1 tegumental cells, T1 secretory bodies were swollen in appearance and appeared to have accumulated within the cells, although active Golgi complexes were absent (Fig. 27). The mitochondria present within the cell were swollen in appearance (Fig. 27). 


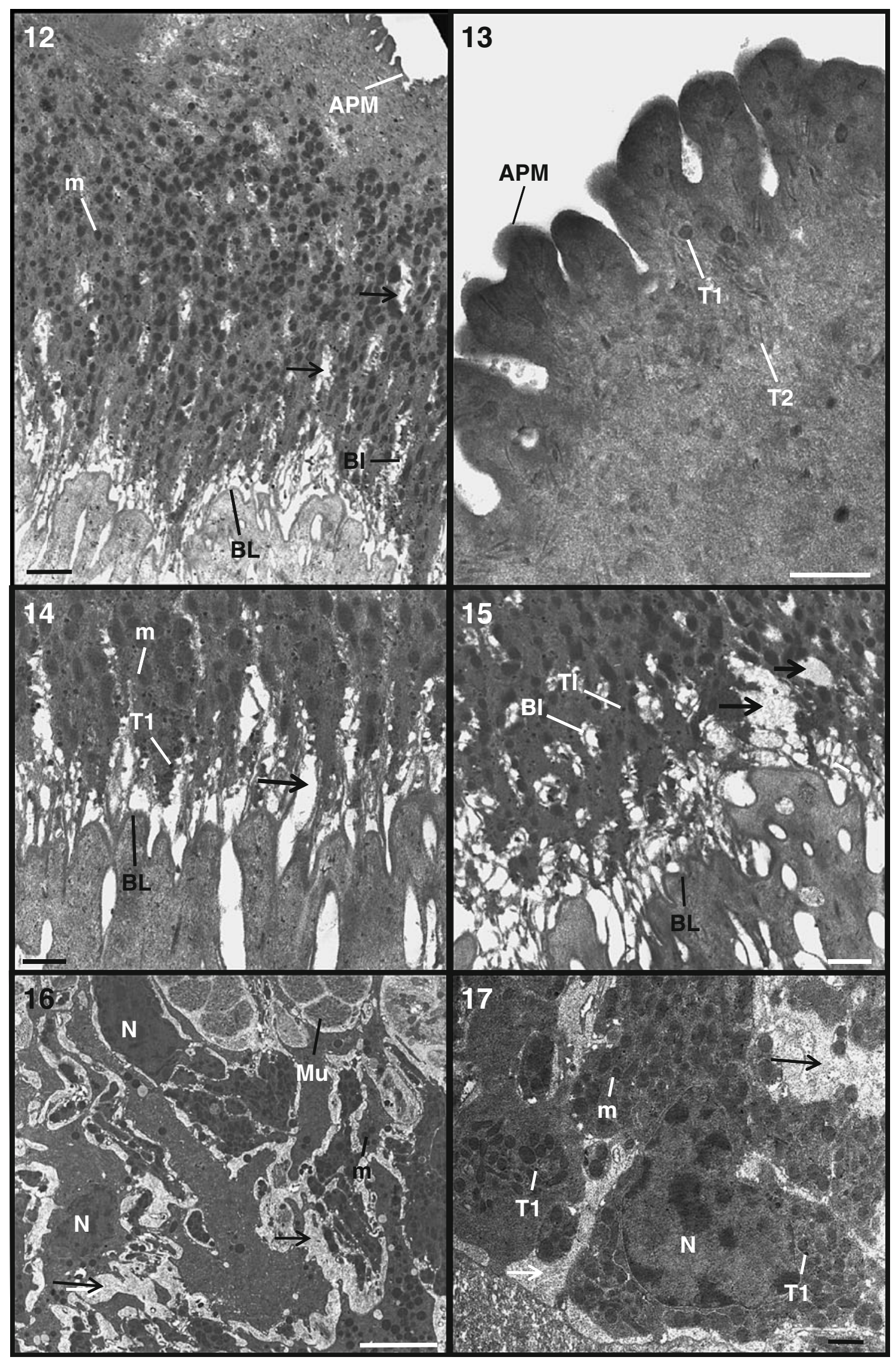




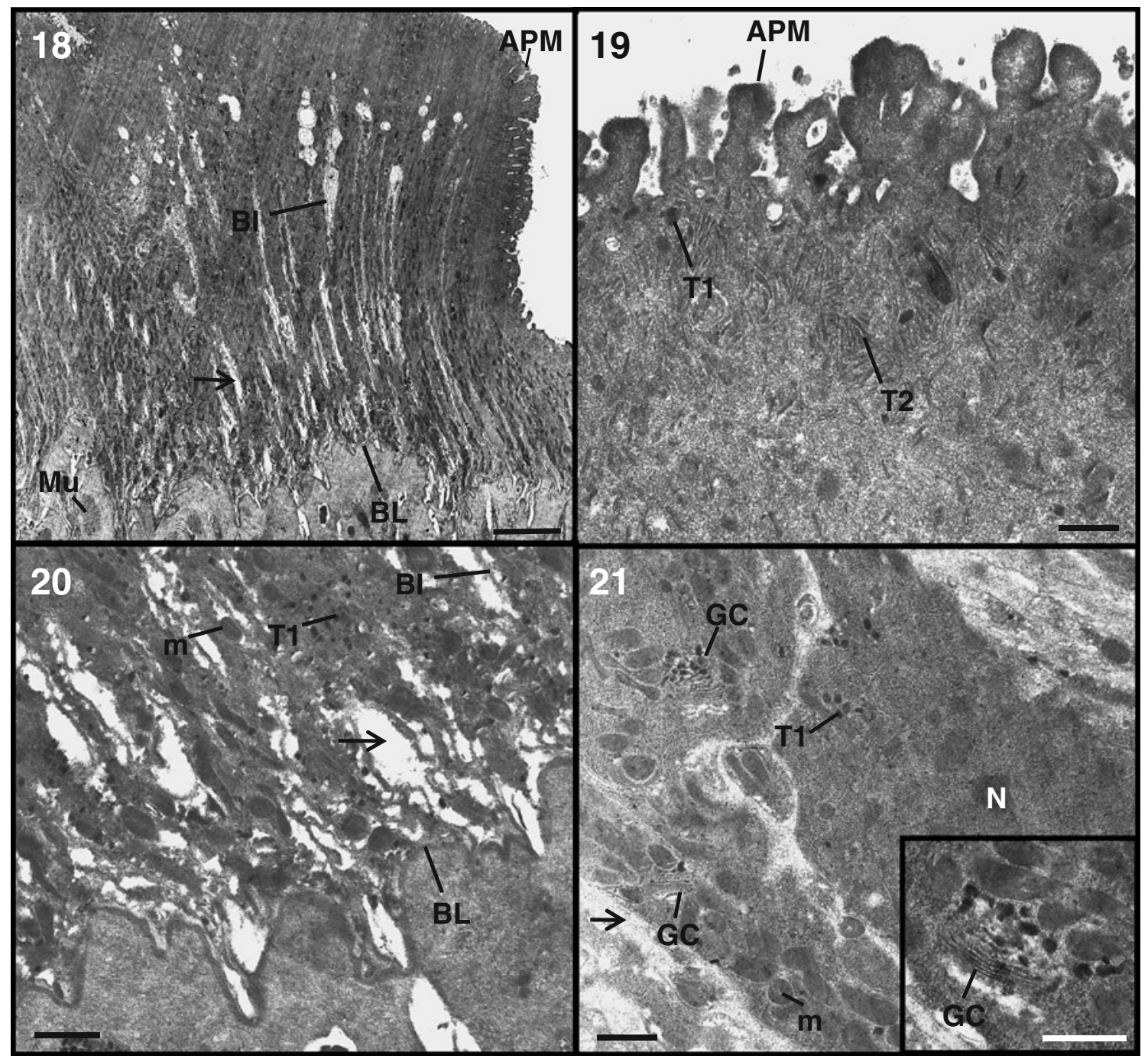

Fig. 18-21 Transmission electron micrographs (TEMs) of the tegumental syncytium, underlying musculature and tegumental cells of adult Fasciola hepatica (Oberon) isolate treated in vitro for $24 \mathrm{~h}$ with KTZ + NADPH + TCBZ 18 TEM of the tegumental syncytium, showing swelling of the mucopolysaccharide masses (arrow), particularly at the distal end of the basal infolds $(B I)$ which are not swollen. $A P M$, apical plasma membrane; $B L$, basal lamina; $M u$, sub-tegumental muscle blocks. Bar $5 \mu \mathrm{m} 19$ A high-power micrograph of the apex of the tegumental syncytium. T1 $(T 1)$ and T2 (T2) secretory bodies are present just beneath the apical plasma membrane (APM). Bar $500 \mathrm{~nm}$

The main changes brought about by drug action and the relative severity of these changes are summarised in Tables 2 and 3.

\section{Discussion}

The results of this investigation have demonstrated that coadministration of KTZ with either TCBZ or TCBZ.SO has a greater effect on the Oberon TCBZ-resistant isolate than on the TCBZ-susceptible Cullompton isolate. While treat-
20 TEM showing the basal region of the tegumental syncytium. Above the basal lamina $(B L)$, the mucopolysaccharide masses (arrow) are swollen, but the basal infolds $(B I)$ remain closed. The mitochondria $(m)$ are also swollen. Numerous T1 $(T 1)$ secretory bodies are present in this region. Bar $1 \mu \mathrm{m} 21$ TEM showing a Type-1 tegumental cell. T1 secretory bodies $(T 1)$ are present within the cell. The Golgi complexes $(G C)$ present retain a relatively normal morphology. Some mitochondria $(\mathrm{m})$ are swollen in appearance. Spaces (arrow) can be seen between the cells. $N$, nucleus. Bar $1 \mu \mathrm{m}$ Inset shows an active well-developed Golgi complex (GC). Bar 500nm ment with TCBZ and (more particularly) TCBZ.SO caused greater disruption of the Cullompton isolate, potentiation of drug action was only observed with the Oberon isolate and was far more distinct with TCBZ.SO than TCBZ. Incubation in $\mathrm{KTZ}$ alone or $\mathrm{KTZ}+\mathrm{NADPH}$ caused some disruption to the ultrastructure of both isolates, although the changes were minimal, with only slight swelling of the mucopolysaccharide masses and secretory bodies.

The syncytium of the Oberon isolate treated with TCBZ alone retained a relatively normal morphology. Only limited swelling of the mucopolysaccharide masses and mitochon- 
dria within the syncytium was observed. "Open" bodies were present beneath the apical plasma membrane: they are known to occur in a stress situation, such as that induced by drug treatment, and are caused by the accelerated release of secretory bodies from the tegumental surface (Rogan and Threadgold 1984). Production of secretory bodies in the tegumental cells was maintained, as active Golgi complexes were present, although there were few $\mathrm{T} 1$ secretory bodies in the Type-1 tegumental cells. After incubation in KTZ+TCBZ, swelling of the mucopolysaccharide masses in the syncytium and of the mitochondria throughout the tegumental system was exacerbated and beneath the basal lamina spacing between the tegumental cells was evident.

Treatment with TCBZ.SO alone led to a similar level of disruption as that induced by TCBZ, but co-incubation with KTZ led to a dramatic increase in the degree of disruption observed. The major change in the tegumental syncytium was the severe swelling of the basal infolds and associated mucopolysaccharide masses. This is indicative of disruption to the osmoregulatory function of the tegument (Fairweather et al. 1999). Similar observations have been made in previous studies involving TCBZ.SO (Stitt and Fairweather 1994; Halferty et al. 2009a) and various other fasciolicides (Fairweather et al. 1986; Skuce et al. 1987; Skuce and Fairweather 1990; Anderson and Fairweather 1995; Meaney et al. 2004, 2005, 2007; McConville et al. 2006, 2007, 2008, 2009; McKinstry et al. 2007, 2009; Halferty et al. 2009b). The severe swelling of the basal infolds would account for the general swelling of the tegument observed in the previous SEM study (Devine et al. 2010c); if allowed to continue, this would lead to the sloughing of the tegument. Within the syncytium, secretory bodies accumulated just beneath the apical plasma membrane. This is indicative of a stress response by the fluke and is a common reaction to treatment with other fasciolicidal drugs, as it serves as a survival mechanism to replace damaged tegument (Fairweather et al. 1986; Stitt and Fairweather 1994; Buchanan et al. 2003; Meaney et al. 2004, 2005, 2007; McConville et al. 2006, 2007, 2008, 2009; McKinstry et al. 2007, 2009; Halferty et al. 2009a, b; O'Neill et al. 2009; Toner et al. 2009, 2010a). Within the tegumental cells, active Golgi complexes were absent and secretory bodies seem to have accumulated within the cells, indicating that their transport to the syncytium had been disrupted. Moreover, the T1 secretory bodies were swollen and abnormal, which suggests that their production had been severely affected. The spacing observed between the cells highlights the possible disruption to energy-dependent ion pumps which would lead to the influx of water into the fluke, causing the basal infolds to swell and the spacing between cells in the subtegmental region (Threadgold and Brennan 1978; Skuce et al. 1987). Internal flooding of the tissues has been observed in a number of drug studies on $F$. hepatica (Fairweather et al.
1986; Stitt and Fairweather 1994; Anderson and Fairweather 1995; McKinstry et al. 2007, 2009; Meaney et al. 2007; Halferty et al. 2009a; Toner et al. 2010b).

With the Cullompton isolate, incubation in TCBZ alone resulted in limited swelling of the basal infolds, mucopolysaccharide masses, and mitochondria in the syncytium (Halferty et al. 2009a). The decline in the number of secretory bodies observed in the syncytium could be attributed to the disruption of the Golgi complexes and the reduced numbers of secretory bodies within the tegumental cells (Halferty et al. 2009a). Co-incubation of KTZ with TCBZ led to no potentiation of drug action in the Cullompton isolate. While there was greater swelling of the basal infolds with the drug combination, there was no reduction in number of secretory bodies in the tegumental cells, as seen following treatment with TCBZ alone. The increase in the swelling of the basal infolds and the spacing between the tegumental cells again would suggest a disruption to the osmoregulatory system within the parasite, as described above.

Following treatment in TCBZ.SO alone, there was greater disruption to the Cullompton isolate than was seen with TCBZ treatment alone. That is, there was greater swelling of the basal infolds, mitochondria, and cisternae of GER; also, fewer secretory bodies present in the tegumental cells (Halferty et al. 2009a). When TCBZ.SO was combined with KTZ, there was little potentiation of drug action: in fact, overall there was less disruption than with TCBZ.SO alone. The only feature that was greater following combination treatment was the spacing between the cells in the sub-tegumental region.

The internal changes observed in the tegumental syncytium of the Oberon isolate link well with the changes of surface morphology that were seen in a previous SEM study using the same drug and inhibitor combinations (Devine et al. 2010c). The swelling and furrowing observed after incubation in KTZ and TCBZ.SO can be linked to the disruption of the osmoregulatory system in the tegumental syncytium, as evidenced by the severe swelling of the basal infolds and the flooding of the subtegumental tissues. The release of damaged areas of the surface membrane would lead to the blebbing seen in the previous SEM study and the accumulation of secretory bodies beneath the apical plasma membrane would indicate that the fluke is trying to repair areas damaged by drug action. This action would not be maintained indefinitely by the fluke as the transport of the secretory bodies needed for membrane repair had been disrupted and the T1 secretory bodies had accumulated within the tegumental cells.

Some of the ultrastructural changes seen in the TCBZresistant Oberon isolate after incubation with $\mathrm{KTZ}$ and TCBZ.SO mirror changes recorded in a previous study using piperonyl butoxide (PB), another CYP 450 inhibitor (Devine et al. 2011a). The abnormal secretory bodies and spacing between the tegumental cells are specific changes observed when TCBZ.SO is combined with KTZ 


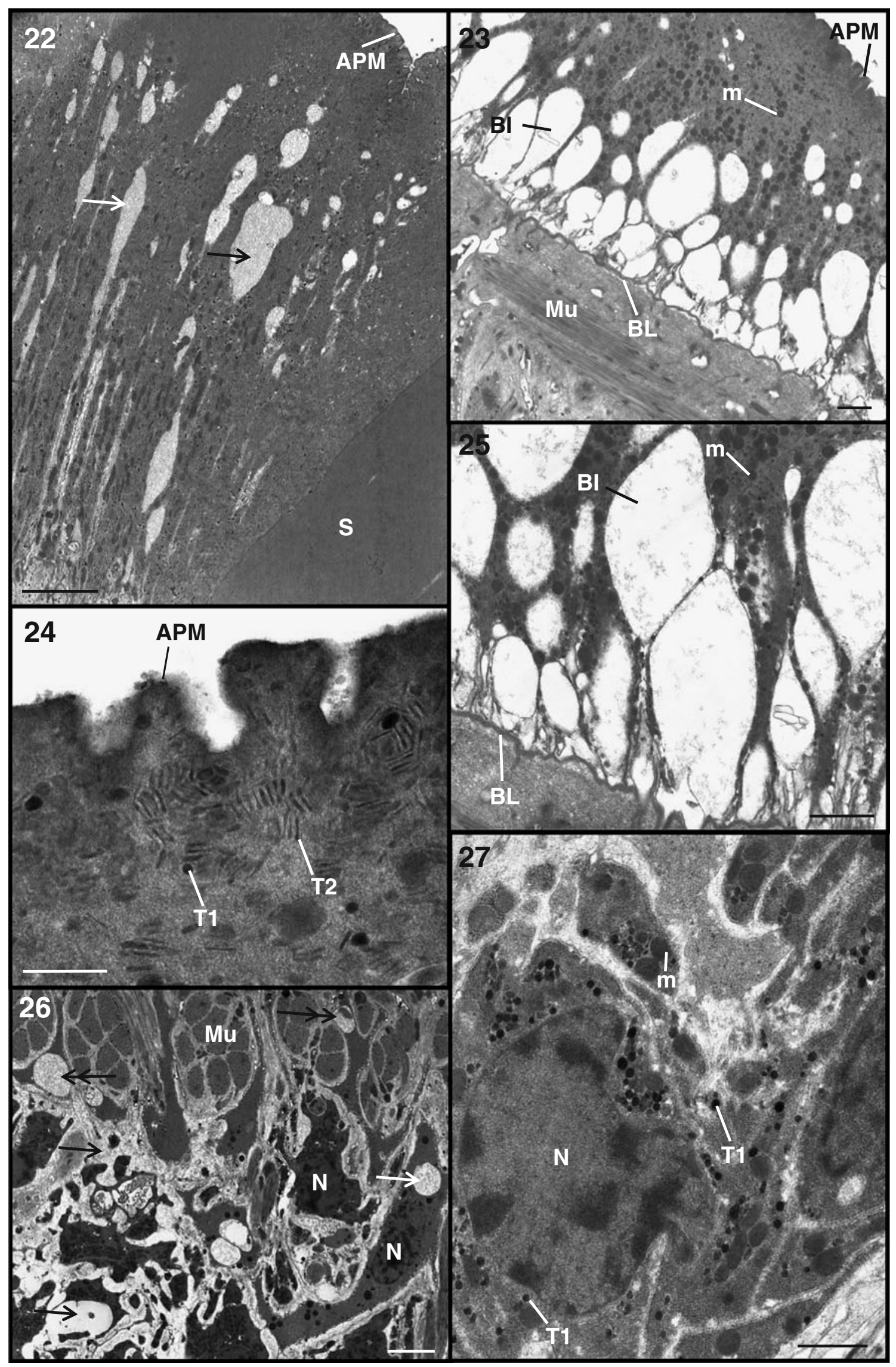


4Fig. 22-27 Transmission electron micrographs (TEMs) of the tegumental syncytium, underlying musculature and tegumental cells of adult Fasciola hepatica (Oberon) isolate treated in vitro for $24 \mathrm{~h}$ with $\mathrm{KTZ}+\mathrm{NADPH}+\mathrm{TCBZ} . \mathrm{SO} 22$ TEM of the tegumental syncytium showing swelling of the mucopolysaccharide masses (arrows) towards the apex of the syncytium. $S$, spine; $A P M$, apical plasma membrane. Bar $5 \mu \mathrm{m} 23$ TEM showing the full depth of the tegumental syncytium, from the apical plasma membrane $(A P M)$ to the basal lamina $(B L)$. The basal infolds $(B I)$ are severely swollen. Mitochondria $(m)$ are present throughout the syncytium, but appear slightly swollen. The underlying muscle $(M u)$ retains a relatively normal morphology. Bar $2 \mu \mathrm{m} 24 \mathrm{~A}$ high-power micrograph of the apex of the tegumental syncytium. There is an accumulation of secretory bodies, mainly $\mathrm{T} 2$ secretory bodies (T2), beneath the apical plasma membrane $(A P M)$. T1, T1 secretory bodies. Bar $500 \mathrm{~nm} 25$ TEM showing the basal region of the tegumental syncytium. Above the basal lamina $(B L)$, the basal infolds $(B I)$ are severely swollen. The mitochondria $(m)$ are also swollen. Bar $2 \mu \mathrm{m} 26$ Low-power micrograph of the sub-tegumental muscle $(M u)$ and tegumental cells. Spaces (arrows) are present between the tegumental cells and muscle blocks (double arrows). The nuclei $(N)$ of the cells retain a normal morphology. Bar $5 \mu \mathrm{m} 27$ TEM showing a Type-1 tegumental cell. T1 (Tl) secretory bodies, which are swollen in appearance, have accumulated within the cell. The mitochondria $(m)$ present are swollen and rounded in appearance. Bar $1 \mu \mathrm{m}$

and $\mathrm{PB}$ that are not seen with the FMO inhibitor, methimazole (MTZ). However, previous studies with MTZ revealed changes commonly seen with all three inhibitors, namely, severe swelling of the basal infolds and associated mucopolysaccharide masses, swelling of the mitochondria and altered numbers of secretory bodies at the apex of the syncytium (Devine et al. 2010b). Moreover, in the tegumental cells, disruption of the Golgi complexes, impaired production of secretory bodies and swelling of the mitochondria are changes common to the three drugs. So, the combined data from these studies show that metabolic inhibition has an effect on the fluke's ability to maintain normal functioning of the tegumental system in the presence of drug action (Devine et al. 2009, 2010a, b, c, 2011a).

A number of studies have involved the use of metabolic inhibitors in an attempt to enhance the pharmacokinetic profile of antiparasitic drugs, extend their active lifespan and so potentially increase their efficacy. Specifically, KTZ has been used in sheep to successfully enhance the bioavailability of TCBZ (Virkel et al. 2009). Thus, coadministration of KTZ with TCBZ led to a higher peak plasma concentration of TCBZ.SO than that measured following TCBZ treatment alone and so enhanced the bioavailability of TCBZ.SO in sheep (Virkel et al. 2009). The enhancement in the pharmacokinetic profile could lead to a higher efficacy against the fluke, although this has not yet been proven. Greater efficacy with benzimidazole plus inhibitor combinations has been demonstrated in other studies (Benchaoui and McKellar 1996; López-García et al. 1998; Sánchez-Bruni et al. 2005). This and the potentiation of drug availability observed in a variety of in vivo studies has led a number of workers to propose the use of such drug combinations as a strategy to deal with drug resistance (Lanusse and Prichard 1993; Lanusse et al. 1995; Benchaoui and McKellar 1996; Dupuy et al. 2003; Sánchez-Bruni et al. 2005; Alvinerie et al. 2008; Wisedpanichkij et al. 2009).

While KTZ is a recognised CYP 450 inhibitor (Newton et al. 1995; Pelkonen et al. 2008), it is also regarded as an inhibitor of Pgp-linked drug efflux pumps (Siegsmund et al. 1994; Zhang et al. 1998; Kim et al. 1999; Wang et al. 2002; Ward et al. 2004; Kageyama et al. 2005). Over-expression of Pgp has been linked to the development of resistance against a number of anthelmintics (Xu et al. 1998; Molento and Prichard 1999; Kerboeuf et al. 2003; Wolstenholme et al. 2004; Prichard and Roulet 2007; James and Davey 2009; James et al. 2009; Messerli et al. 2009). Recently, evidence has been presented for the role of Pgp in the mechanism of resistance to TCBZ in F. hepatica (Alvarez et al. 2005; Mottier et al. 2006; Fairweather et al. 2009). This would point towards the mechanism of resistance to TCBZ as being multi-factorial within the fluke. The accumulation of TCBZ and TCBZ.SO has been shown to be significantly reduced in the TCBZ-resistant Sligo isolate (Alvarez et al. 2005; Mottier et al. 2006). Reduced drug uptake would lower the effective concentrations of TCBZ metabolites within the fluke and this, combined with more rapid metabolism and inactivation of the compounds, would reduce their ability to reach the target molecule in sufficient concentration for effective drug action. If KTZ acted on both the CYP 450 pathway and Pgp pumps, thus blocking drug metabolism and drug efflux, it would raise drug levels within the parasite and allow for more sustained drug action. As with the use of metabolic inhibitors, the combined use of anthelmintics plus Pgp inhibitors such as KTZ and verapamil has been advanced as a strategy to deal with drug resistance (Alvarez et al. 2006; Hugnet et al. 2007; Alvinerie et al. 2008; Lespine et al. 2008, 2009). Enhanced activity and efficacy of such combinations has been demonstrated by Molento and Prichard (1999), Bartley et al. (2009), and Lifschitz et al. (2010), for example.

In conclusion, this investigation has shown that it is possible to convert a TCBZ-resistant isolate to a more susceptible state using the CYP 450 inhibitor, KTZ. In order to investigate this further, it was considered worthwhile to examine the effects of co-administration of KTZ and TCBZ over a 4-day period in a rat host and so observe the morphological changes in vivo; the results of this study will be published separately (Devine et al. 2011b). Modulating drug activity both within the host and parasite offers a new avenue to try and delay drug resistance and maintain the efficacy of triclabendazole, as currently no new drugs to treat $F$. hepatica infections are in development. 
Table 2 Cullompton isolate of Fasciola hepatica

\begin{tabular}{|c|c|c|c|c|c|c|}
\hline \multirow[t]{2}{*}{ Disruption } & \multicolumn{6}{|c|}{ Treatment } \\
\hline & KTZ & KTZ+NADPH & TCBZ & $\begin{array}{l}\text { KTZ+NADPH+ } \\
\text { TCBZ }\end{array}$ & $\begin{array}{l}\mathrm{KTZ}+\mathrm{NADPH}+\mathrm{TCBZ} \\
\mathrm{SO}\end{array}$ & TCBZ.SO \\
\hline \multicolumn{7}{|l|}{ Changes in syncytium } \\
\hline Blebbing & - & - & - & - & - & - \\
\hline Presence of "open" bodies & - & - & - & - & - & - \\
\hline Altered numbers of secretory bodies at apex & - & - & + & - & - & + \\
\hline Swelling of basal infolds & - & - & + & ++ & - & ++ \\
\hline Swelling of mucopolysaccharide masses & + & + & + & + & + & + \\
\hline Swelling of mitochondria & - & - & + & ++ & + & ++ \\
\hline \multicolumn{7}{|l|}{ Changes in tegumental cells } \\
\hline Alteration in number of secretory bodies & - & - & + & - & - & ++ \\
\hline $\begin{array}{l}\text { Reduction in number and size of } \\
\text { Golgi complexes }\end{array}$ & - & - & + & - & - & + \\
\hline Swelling of secretory bodies & + & + & - & - & - & - \\
\hline Swelling of cisternae of GER & - & - & - & - & - & ++ \\
\hline Swelling of mitochondria & - & - & + & + & ++ & ++ \\
\hline Spacing between cells & - & - & - & + & ++ & - \\
\hline Total & 2 & 2 & 7 & 7 & 6 & 13 \\
\hline
\end{tabular}

Summary of changes to the tegumental system following different drug treatments

$(-)$ no noticeable disruption, $(+)$ general/mild disruption, $(++)$ severe disruption, $(+++)$ very severe disruption. KTZ ketoconazole, $N A D P H$ nicotinamide adenine dinucleotide phosphate, TCBZ triclabendazole, TCBZ.SO triclabendazole sulphoxide, GER granular endoplasmic reticulum

Table 3 Oberon isolate of Fasciola hepatica

\begin{tabular}{|c|c|c|c|c|c|c|}
\hline \multirow[t]{2}{*}{ Disruption } & \multicolumn{6}{|c|}{ Treatment } \\
\hline & KTZ & $\mathrm{KTZ+NADPH}$ & TCBZ & $\mathrm{KTZ}+\mathrm{NADPH}+\mathrm{TCBZ}$ & $\begin{array}{l}\text { KTZ+NADPH+TCBZ. } \\
\text { SO }\end{array}$ & $\begin{array}{l}\text { TCBZ. } \\
\text { SO }\end{array}$ \\
\hline \multicolumn{7}{|l|}{ Changes in Syncytium } \\
\hline Blebbing & - & - & - & - & - & + \\
\hline Presence of "open" bodies & - & - & + & - & - & + \\
\hline $\begin{array}{l}\text { Altered numbers of secretory } \\
\text { bodies at apex }\end{array}$ & - & - & - & - & ++ & + \\
\hline Swelling of basal infolds & - & - & - & - & +++ & - \\
\hline Swelling of mucopolysaccharide masses & + & + & + & ++ & +++ & + \\
\hline Swelling of mitochondria & - & - & + & ++ & +++ & + \\
\hline \multicolumn{7}{|l|}{ Changes in tegumental cells } \\
\hline Alteration in number of secretory bodies & - & - & + & - & ++ & - \\
\hline $\begin{array}{l}\text { Reduction in number and size } \\
\text { of Golgi complexes }\end{array}$ & - & - & - & - & +++ & + \\
\hline Swelling of secretory bodies & + & + & - & - & ++ & - \\
\hline Swelling of cisternae of GER & - & - & + & - & - & - \\
\hline Swelling of mitochondria & - & - & + & ++ & +++ & - \\
\hline Spacing between cells & - & - & - & + & ++ & - \\
\hline Total & 2 & 2 & 6 & 7 & 23 & 6 \\
\hline
\end{tabular}

Summary of changes to the tegumental system following different drug treatments

$(-)$ no noticeable disruption, $(+)$ general/mild disruption, $(++)$ severe disruption, $(+++)$ very severe disruption. KTZ ketoconazole, NADPH nicotinamide adenine dinucleotide phosphate, TCBZ triclabendazole, TCBZ.SO triclabendazole sulphoxide, GER granular endoplasmic reticulum 
Acknowledgements This investigation was supported by a DARDNI Postgraduate Studentship to Catherine Devine. It was also partially supported by a grant from the European Union (DELIVER grant, no. FOOD-CT-200X-023025) and by a BBSRC/Defra grant (C00082X/1).

\section{References}

Alvarez LI, Solana HD, Mottier ML, Virkel GL, Fairweather I, Lanusse CE (2005) Altered drug influx/efflux and enhanced metabolic activity in triclabendazole-resistant liver flukes. Parasitology 131:501-510

Alvarez AI, Merino G, Molina AJ, Pulido MM, McKellar QA, Prieto JG (2006) Role of ABC transporters in veterinary drug research and parasite resistance. Curr Drug Deliv 3:199-206

Alvinerie M, Dupuy J, Kiki-Mvouaka S, Sutra J-F, Lespine A (2008) Ketoconazole increases the plasma levels of ivermectin in sheep. Vet Parasitol 157:117-122

Anderson HR, Fairweather I (1995) Fasciola hepatica: ultrastructural changes to the tegument of juvenile flukes following incubation in vitro with the deacetylated (amine) metabolite of diamphenethide. Int J Parasitol 25:319-333

Bartley DJ, Mc Allister H, Bartley Y, Dupuy J, Menez C, Alvinerie M, Jackson F, Lespine A (2009) P-glycoprotein interfering agents potentiate ivermectin susceptibility in ivermectin sensitive and resistant isolates of Teladorsagia circumcinta and Haemonchus contortus. Parasitology 136:1081-1088

Benchaoui HA, McKellar QA (1996) Interaction between fenbendazole and piperonyl butoxide: pharmacokinetic and pharmacodynamic implications. J Pharm Pharmacol 48:753-759

Bourrie M, Meunier V, Berger Y, Fabre G (1996) Cytochrome P450 isoform inhibitors as a tool for the investigation of metabolic reactions catalyzed by human liver microsomes. J Pharmacol Exp Ther 277:321-332

Buchanan JF, Fairweather I, Brennan GP, Trudgett A, Hoey EM (2003) Surface and internal tegumental changes induced by treatment in vitro with the sulphoxide metabolite of albendazole ("Valbazen"). Parasitology 126:141-153

Cvilink V, Lamka J, Skálová L (2009) Xenobiotic metabolizing enzymes and metabolism of anthelmintics in helminths. Drug Metab Rev 41:8-26

Devine C, Brennan GP, Lanusse CE, Alvarez LI, Trudgett A, Hoey E, Fairweather I (2009) Effect of the metabolic inhibitor, methimazole on the drug susceptibility of a triclabendazole-resistant isolate of Fasciola hepatica. Parasitology 136:183-192

Devine C, Brennan GP, Lanusse CE, Alvarez LI, Trudgett A, Hoey E, Fairweather I (2010a) Inhibition of cytochrome P450-mediated metabolism enhances ex vivo susceptibility of Fasciola hepatica to triclabendazole. Parasitology 137:871-880

Devine C, Brennan GP, Lanusse CE, Alvarez LI, Trudgett A, Hoey E, Fairweather I (2010b) Potentiation of triclabendazole sulphoxideinduced tegumental disruption by methimazole in a triclabendazole-resistant isolate of Fasciola hepatica. Parasitol Res 106:1351-1363

Devine C, Brennan GP, Lanusse CE, Alvarez LI, Trudgett A, Hoey E, Fairweather I (2010c) Enhancement of the drug susceptibility of a triclabendazole-resistant isolate of Fasciola hepatica using the metabolic inhibitor ketoconazole. Parasitol Res 107:337-353

Devine C, Brennan GP, Lanusse CE, Alvarez LI, Trudgett A, Hoey EM, Fairweather I (2011a) Piperonyl butoxide enhances triclabendazole action against triclabendazole-resistant Fasciola hepatica. Parasitology 138:224-236

Devine C, Brennan GP, Lanusse CE, Alvarez LI, Trudgett A, Hoey E, Fairweather I (2011b) Enhancement of triclabendazole action in vivo against a triclabendazole-resistant isolate of Fasciola hepatica by co-treatment with ketoconazole. Vet Parasitol 177:305-315

Dupuy J, Larrieu G, Sutra JF, Lespine A, Alvinerie M (2003) Enhancement of moxidectin bioavailability in lamb by a natural flavonoid: quercetin. Vet Parasitol 112:337-347

Fairweather I (2011) Liver fluke isolates: a question of provenance. Vet Parasitol 176:1-8

Fairweather I, Anderson HR, Threadgold LT (1986) Fasciola hepatica: tegumental changes induced in vitro by the deacetylated (amine) metabolite of diamphenethide. Exp Parasitol 62:336-348

Fairweather I, Threadgold LT, Hanna REB (1999) Development of Fasciola hepatica in the mammalian host. In: Dalton JP (ed) Fasciolosis. CAB International, Wallingford, pp 47-111

Fairweather I, Meaney M, Savage J, Brennan G, Hoey E, Trudgett A (2009) Do drug efflux pumps play a role in the resistance of Fasciola hepatica to triclabendazole? $23^{\text {rd }}$ International Conference of the WAAVP, Calgary Canada, August 2009. Abst. CS35.2

Halferty L, Brennan GP, Trudgett A, Hoey EM, Fairweather I (2009a) The relative activity of triclabendazole metabolites against the liver fluke, Fasciola hepatica. Vet Parasitol 159:126-138

Halferty L, O'Neill JF, Brennan GP, Keiser J, Fairweather I (2009b) Electron microscopical study to assess the in vitro effects of the synthetic trioxolane OZ78 against the liver fluke, Fasciola hepatica. Parasitology 136:1325-1337

Hennessy DR, Lacey E, Steel JW, Prichard RK (1987) The kinetics of triclabendazole disposition in sheep. J Vet Pharmacol Ther 10:64-72

Hugnet C, Lespine A, Alvinerie M (2007) Multiple oral dosing of ketoconazole increases dog exposure to ivermectin. J Pharm Pharmaceut Sci 10:311-318

James CE, Davey MW (2009) Increased expression of ABC transport proteins is associated with ivermectin resistance in the model nematode Caenorhabditis elegans. Int J Parasitol 39:213-220

James CE, Hudson AL, Davey MW (2009) An update on Pglycoprotein and drug resistance in Schistosoma mansoni. Trends Parasitol 25:538-539

Kageyama M, Namiki H, Fukushima H, Ito Y, Shibata N, Takada K (2005) In vivo effects of cyclosporine A and ketoconazole on the pharmacokinetics of representative substrates for P-glycoprotein and cytochrome P450 (CYP) 3A in rats. Biol Pharm Bull 28:316-322

Kerboeuf D, Blackhall W, Kaminsky R, von Samson-Himmelstjerna G (2003) P-glycoprotein in helminths: function and perspectives for anthelmintic treatment and reversal of resistance. Int $\mathrm{J}$ Antimicrob Agents 22:332-346

Kim RB, Wandel C, Leake B, Cvetkovic M, Fromm MF, Dempsye PJ, Roden MM, Belas F, Chaudhary AK, Roden DM, Wood AJ, Wilkinson GR (1999) Interrelationship between substrates and inhibitors of human CYP3A and P-glycoprotein. Pharm Res $16: 408-414$

Lanusse CE, Prichard RK (1993) Clinical pharmacokinetics and metabolism of benzimidazole anthelmintics in ruminants. Drug Metab Rev 25:235-279

Lanusse CE, Gascon LH, Prichard RK (1995) Influence of the antithyroid compound methimazole on the plasma disposition of fenbendazole and oxfendazole in sheep. Res Vet Sci 58:222-226

Lespine A, Alvinerie M, Vercruysse J, Prichard RK, Geldhof P (2008) ABC transporter modulation: a strategy to enhance the activity of macrocyclic lactone anthelmintics. Trends Parasitol 24:293-298

Lespine A, Dupuy J, Alvinerie M, Comera C, Nagy T, Krajcsi P, Orlowski S (2009) Interaction of macrocyclic lactones with the multidrug transporters: the bases of the pharmacokinetics of lipid-like drugs. Curr Drug Metab 10:272-288 
Lifschitz A, Entrocasso C, Alvarez L, Lloberas M, Ballent M, Manazza G, Virkel G, Borda B, Lanusse C (2010) Interference with P-glycoprotein improves ivermectin activity against adult resistant nematodes in sheep. Vet Parasitol 172:291-298

López-García ML, Torrado S, Torrado S, Martínez AR, Bolás F (1998) Methimazole-mediated enhancement of albendazole oral bioavailability and anthelmintic effects against parenteral stages of Trichinella spiralis in mice: the influence of the dose-regime. Vet Parasitol 75:209-219

McConville M, Brennan GP, McCoy M, Castillo R, HernándezCampos A, Ibarra F, Fairweather I (2006) Adult triclabendazoleresistant Fasciola hepatica: surface and subsurface tegumental responses to in vitro treatment with the sulphoxide metabolite of the experimental fasciolicide compound alpha. Parasitology 133:195-208

McConville M, Brennan GP, McCoy M, Castillo R, Hernández-Campos A, Ibarra F, Fairweather I (2007) Immature triclabendazole-resistant Fasciola hepatica: tegumental responses to in vitro treatment with the sulphoxide metabolite of the experimental fasciolicide compound alpha. Parasitol Res 100:365-377

McConville M, Brennan GP, Flanagan A, Edgar HWJ, McCoy M, Castillo R, Hernández-Campos A, Fairweather I (2008) Surface and internal tegumental changes in juvenile Fasciola hepatica following treatment in vivo with the experimental fasciolicide, compound alpha. Vet Parasitol 153:52-64

McConville M, Brennan GP, Flanagan A, Edgar HWJ, Castillo R, Hernández-Campos A, Fairweather I (2009) Ultrastructural changes to the tegumental system and the gastrodermal cells in adult Fasciola hepatica following in vivo treatment with the experimental fasciolicide, compound alpha. Parasitology 136:665-680

McKinstry BD (2008) Ultrastructural changes observed in Fasciola hepatica following treatment with nitroxynil and triclabendazole, alone and in combination. $\mathrm{PhD}$ Thesis, The Queen's University of Belfast

McKinstry B, Brennan GP, Halferty L, Forbes AB, Fairweather I (2007) Ultrastructural changes induced in the tegument and gut of Fasciola hepatica following in vivo and in vitro drug treatment with nitroxynil (Trodax). Parasitol Res 101:929-941

McKinstry B, Halferty L, Brennan GP, Fairweather I (2009) Morphological response of triclabendazole-resistant isolates of Fasciola hepatica to treatment in vitro with nitroxynil (Trodax). Parasitol Res 104:645-655

Meaney M, Fairweather I, Brennan GP, Forbes AB (2004) Transmission electron microscope study of the ultrastructural changes induced in the tegument and gut of Fasciola hepatica following treatment with clorsulon. Parasitol Res 92:232-241

Meaney M, Haughey S, Brennan GP, Fairweather I (2005) Ultrastructural observations on oral ingestion and trans-tegumental uptake of clorsulon by the liver fluke, Fasciola hepatica. Parasitol Res 95:201-212

Meaney M, Allister J, McKinstry B, McLauglin K, Brennan GP, Forbes AB, Fairweather I (2007) Fasciola hepatica: ultrastructural effects of a combination of triclabendazole and clorsulon against mature fluke. Parasitol Res 100:1091-1104

Messerli SM, Kasinathan RS, Morgan W, Spranger S, Greenberg RM (2009) Schistosoma mansoni P-glycoprotein levels increase in response to praziquantel exposure and correlate with reduced praziquantel susceptibility. Mol Biochem Parasitol 167:54-59

Molento MB, Prichard RK (1999) Effects of the multidrug-reversing agents verapamil and CL 347,099 on the efficacy of ivermectin or moxidectin against unselected and drug-selected strains of Haemonchus contortus in jirds. Parasitol Res 85:1007-1011

Mottier L, Virkel G, Solana H, Alvarez L, Salles J, Lanusse C (2004) Triclabendazole biotransformation and comparative diffusion of the parent drug and its oxidized metabolites into Fasciola hepatica. Xenobiotica 34:1043-1047
Mottier L, Alvarez L, Ceballos L, Lanusse C (2006) Drug transport mechanisms in helminth parasites: passive diffusion of benzimidazole anthelmintics. Exp Parasitol 113:49-57

Newton DJ, Wang RW, Lu AYH (1995) Cytochrome P450 inhibitors: evaluation of specificities in the in vitro metabolism of therapeutic agents by human liver microsomes. Drug Metab Dispos 23:154-158

O'Neill JF, Johnston RC, Halferty L, Brennan GP, Keiser J, Fairweather I (2009) Adult triclabendazole-resistant Fasciola hepatica: morphological responses to in vivo treatment with artemether in the rat model. J Helminthol 83:151-163

Pelkonen O, Turpeinen M, Hakkola M, Honkakoski P, Hukkanen J, Raunio H (2008) Inhibition and induction of human cytochrome P450 enzymes: current status. Arch Toxicol 82:667-715

Prichard RK, Roulet A (2007) ABC transporters and $\beta$-tubulin in macrocyclic lactone resistance: prospects for marker development. Parasitology 134:1123-1132

Robinson MW, Lawson J, Trudgett A, Hoey EM, Fairweather I (2004) The comparative metabolism of triclabendazole sulphoxide by triclabendazole-susceptible and triclabendazole-resistant Fasciola hepatica. Parasitol Res 92:205-210

Rogan MT, Threadgold LT (1984) Fasciola hepatica: tegumental changes as a result of lectin binding. Exp Parasitol 57:248-260

Sánchez-Bruni SFS, Fusé LA, Moreno L, Saumell CA, Álvarez LI, Fiel C, McKellar QA, Lanusse CE (2005) Changes to oxfendazole chiral kinetics and anthelmintic efficacy induced by piperonyl butoxide in horses. Equine Vet J 37:257-262

Siegsmund MJ, Cardarelli C, Akasentjevich I, Sugimoto Y, Pastan I, Gottesman MM (1994) Ketoconazole effectively reverses multidrug resistance in highly resistant KB cells. J Urol 151:485-491

Skuce PJ, Fairweather I (1990) The effect of the hydrogen ionophore closantel upon the pharmacology and ultrastructure of the adult fluke Fasciola hepatica. Parasitol Res 76:241-250

Skuce PJ, Anderson HR, Fairweather I (1987) The interaction between the deacetylated (amine) metabolite of diamphenethide (DAMD) and cytochemically demonstrable $\mathrm{Na}^{+} / \mathrm{K}^{+}$ATPase activity in the tegument of Fasciola hepatica. Parasitol Res 74:161-167

Stitt A, Fairweather I (1994) The effect of the sulphoxide metabolite of triclabendazole ('Fasinex') on the tegument of mature and immature stages of the liver fluke, Fasciola hepatica. Parasitology 108:555567

Threadgold LT, Brennan G (1978) Fasciola hepatica: basal infolds and associated vacuoles of the tegument. Exp Parasitol 46:300-316

Toner E, McConvery F, Brennan GP, Meaney M, Fairweather I (2009) A scanning electron microscope study on the route of entry of triclabendazole into the liver fluke, Fasciola hepatica. Parasitology 136:523-535

Toner E, Brennan GP, McConvery F, Meaney M, Fairweather I (2010a) A transmission electron microscope study on the route of entry of triclabendazole into the liver fluke, Fasciola hepatica. Parasitology 137:855-870

Toner E, Brennan GP, Hanna REB, Edgar HWJ, Fairweather I (2010b) Time-dependent changes to the tegumental system and gastrodermis of adult Fasciola hepatica following treatment in vivo with triclabendazole in the sheep host. Vet Parasitol 174:218-227

Virkel G, Lifschitz A, Sallovitz J, Pis A, Lanusse C (2006) Assessment of the main metabolism pathways for the flukicidal compound triclabendazole in sheep. J Vet Pharmacol Ther 29:213-223

Virkel G, Lifschitz A, Sallovitz J, Ballent M, Scarcella S, Lanusse C (2009) Inhibition of cytochrome P450 activity enhances the systemic availability of triclabendazole metabolites in sheep. J Vet Pharmacol Ther 32:79-86

Wang EJ, Lew K, Casciano N, Clement RP, Johnson WW (2002) Interaction of common azole antifungals with $\mathrm{P}$ glycoprotein. Antimicrob Agents Chemother 46:160-165 
Ward KW, Stelman GJ, Morgan JA, Zeigler KS, Azzarano LM, Kehler JR, McSurdy-Freed JE, Proksch JW, Smith BR (2004) Development of an in vivo preclinical screen model to estimate absorption and first-pass hepatic extraction of xenobiotics. II. Use of ketoconazole to identify P-glycoprotein/CYP3A-limited bioavailability in the monkey. Drug Metab Dispos 32:172-177

Wisedpanichkij R, Chaijaroenkul W, Sangsuwan P, Tantisawat J, Boonprasert K, Na-Bangchang K (2009) In vitro antimalarial interactions between mefloquine and cytochrome P450 inhibitors. Acta Trop 112:12-15

Wolstenholme AJ, Fairweather I, Prichard R, von Samson-Himmelstjerna G, Sangster NC (2004) Drug resistance in veterinary helminths. Trends Parasitol 20:469-476
Xu M, Molento M, Blackhall W, Ribeiro P, Beech R, Prichard R (1998) Ivermectin resistance in nematodes may be caused by alteration of P-glycoprotein homolog. Mol Biochem Parasitol 91:327-335

Zhang Y, Hsieh Y, Izumi T, Lin ET, Benet LZ (1998) Effects of ketoconazole on the intestinal metabolism, transport and oral bioavailability of $\mathrm{K} 02$, a novel vinylsulfone peptidomimetic cysteine protease inhibitor and a P450 3A, P-glycoprotein dual substrate, in male Sprague-Dawley rats. J Pharmacol Exp Ther 287:246-252

Zhang W, Ramamoorthy Y, Kilicarslan T, Nolte H, Tyndale RF, Sellers EM (2002) Inhibition of cytochromes P450 by antifungal imidazole derivatives. Drug Metab Dispos 30:314-318 